Original Research Article

\title{
Assessment of knowledge, attitudes and practice among interns about over the counter drugs in a tertiary care hospital in India
}

\author{
Sudipto Chatterjee, R. Vijendra*, K. Girish, Mahesh Kumar Manjeri Koroth
}

Department of Pharmacology,

Kempegowda Institute of Medical Science, Bangalore, India

Received: 18 September 2019

Revised: 11 October 2019

Accepted: 14 October 2019

*Correspondence to:

Dr. R. Vijendra,

Email: vijendra_ramaiah@

yahoo.co.in

Copyright: (C) the author(s), publisher and licensee Medip Academy. This is an openaccess article distributed under the terms of the Creative Commons Attribution NonCommercial License, which permits unrestricted noncommercial use, distribution, and reproduction in any medium, provided the original work is properly cited.

\begin{abstract}
Background: Drugs that are dispensed against a valid prescription issued to a patient by a registered medical practitioner are known as "prescription-only drugs". In India, they have been regulated under schedule H, H1, G, and X of the Drugs and Rules (1945). The drugs which are not included in the list of "prescription-only drugs" are considered to be over-the-counter drugs (OTC). There is no provision for an OTC drug schedule in the Drugs and Cosmetics Rules 1945, and these drugs have higher chances of misuse or abuse. This study was undertaken to assess the knowledge, attitudes and practice among medical interns about OTC drugs in a tertiary care hospital in India.

Methods: This was a cross-sectional study, which was conducted at Kempegowda Institute of Medical Sciences and Research Center, Bangalore, Karnataka, India, from March 2018 to September 2018. A pre-validated questionnaire consisting of 24 questions to assess the knowledge, attitude, and practice was administered to 80 medical interns chosen by simple randomization, out of which 14 questions were related to knowledge, 6 related to attitude and 4 related to the practice. The participants were provided 30 minutes to complete the questionnaire. The data recorded were analyzed using Microsoft Excel.

Results: There were some gaps in the knowledge, attitude and practice among the medical interns about OTC medications.

Conclusions: There is a need for special emphasis on the MBBS curriculum about the use of OTC drugs.
\end{abstract}

Keywords: Attitude, Knowledge, Practice, OTC drugs, Interns

\section{INTRODUCTION}

Over-the-counter (OTC) medications are non-prescription medications, i.e., these medications can be sold directly to a consumer without a prescription from a qualified and registered healthcare professional. ${ }^{1}$ Most of the drugs are sold by a retail pharmacist only against a prescription of a registered medical practitioner. These are "prescriptiononly drugs", and in India, they have been placed in Schedule H, H1, G, and X of the Drugs and Cosmetic Act (1940).

Drugs and Cosmetics Act (1940) states "substances specified in Schedule H and Schedule H1 or Schedule X shall not be sold by retail except on and in accordance with the prescription of a registered medical practitioner and in the case of substances specified in Schedule X, the prescriptions shall be in duplicate, one copy of which shall be retained by the licensee for a period of two years".

The Drugs and Cosmetics Rules (1945) classify drugs into different schedules providing guidelines for storage, sale, display and prescription of drugs under each schedule. The major schedules include:

\section{Schedule $G$}

Includes hormonal and anti-hormonal, anti-diabetic, antineoplastic agents, etc., e.g., metformin, aminopterin, 1asparaginase, bleomycin, busulphan. 


\section{Schedule $\mathrm{H}$}

Drugs are to be sold by retail on the prescription of a registered medical practitioner only. Majority of the prescription drugs are included in this schedule. Presently, there are 536 drugs included in this schedule. E.g., allopurinol, colchicine.

\section{Schedule H1}

Include drugs which need to be very judiciously in order to prevent misuse and/or prevent development of drug resistance. The Government of India on August 30, 2013, had made an amendment to the Drugs and Cosmetics Act of 1940 and introduced the Schedule H1. Drugs included under this schedule are antimicrobial agents including antitubercular drugs and such other drugs which should be used sparingly in the general population. The details of the drugs should be recorded in a separate register at the time of the supply by the pharmacist mentioning the name and address of the prescriber, along with the name of the patient and the name of the drug with the quantity supplied. E.g., alprazolam, doripenam, balofloxacin, ertapenem, buprenorphine, capreomycin, ethionamide, cefdinir, feropenam, cefditoren.

\section{Schedule X}

Include those drugs where the retailer should preserve the prescription for a period of two years. It includes controlled drugs and drugs which have high likelihood of abuse and misuse. E.g., amobarbital, glutethimide pentobarbital, ketamine hydrochloride, amphetamine, meprobamate, phencyclidine, barbital, methamphetamine.

The Drugs and Cosmetics Rules (1945) also mandates that the drug label should contain the texts "Rx" in case of a Schedule H drug; "NRx" in case where the drug falls under the Narcotic Drugs and Psychotropic Substances Act, 1985; and "XRx" in case of a Schedule H drug. These labels shall be in red conspicuously displayed on the left top corner of the label. ${ }^{2}$

Currently, there is no OTC drug schedule in the Drugs and Cosmetics Act. As of now, drugs which are outside schedule $\mathrm{H}, \mathrm{H} 1, \mathrm{G}$, and $\mathrm{X}$ are considered to be an OTC drug. ${ }^{3}$ The likelihood of misuse of drugs is, therefore, more with the OTC drugs. ${ }^{4}$

Some essential characteristics of OTC drugs includes high margin of safety and effectiveness, low potential for misuse and abuse, useful for self-diagnosable, conditions and have adequate labeling for consumers. ${ }^{5}$

\section{Objectives}

The study was undertaken to assess the knowledge, attitudes and practice among medical interns about OTC drugs in a tertiary care hospital in India.

\section{METHODS}

This was a cross-sectional study, which was conducted at Kempegowda Institute of Medical Sciences and Research Center (KIMS and RC), Bangalore, Karnataka, India, from March 2018 to September 2018. A questionnaire was prepared which consisted of 24 questions. Among them, 14 were related to the knowledge, 6 were related to attitude and the remaining 4 questions were related to the practice aspects. ${ }^{4}$ This was validated by logical validation. The study was commenced after obtaining approval from the KIMS institutional ethics committee. The questionnaires were administered to the consenting participants- 80 medical interns of KIMS and RC, Bangalore. Approximately, 30 minutes were provided to the participants for filling up the questionnaires. The data were analyzed using Microsoft Excel.

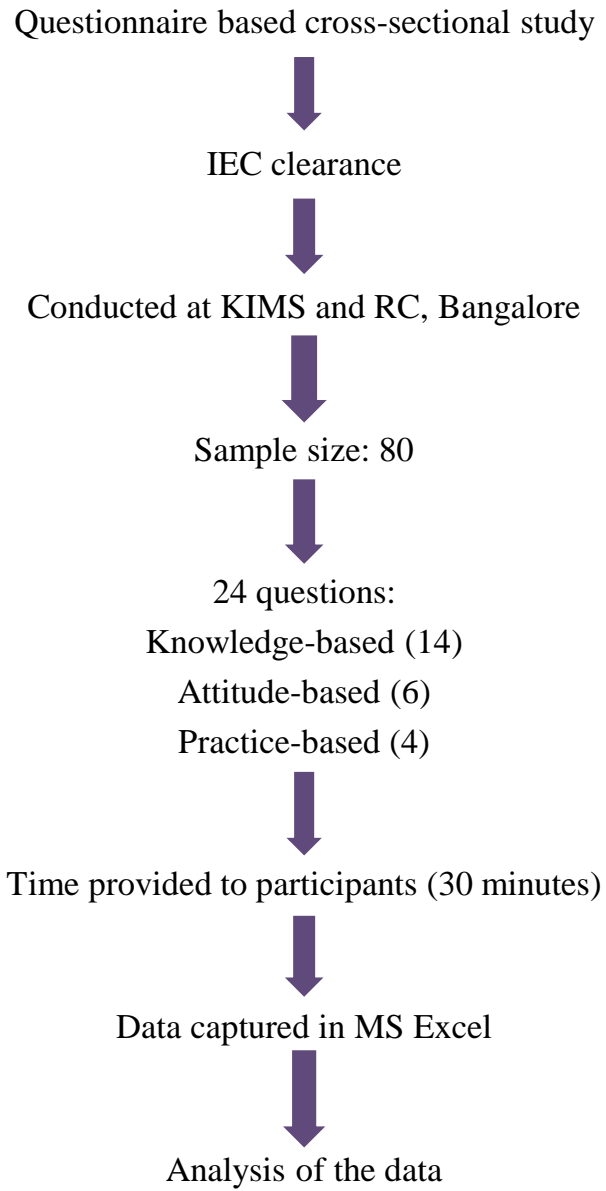

Figure 1: Methodology.

The questionnaire was framed to elicit the knowledge of the participants (14 questions) including knowledge about the drug schedules, commonly used drugs such as analgesics, antimicrobials and sedatives, their appropriateness of usage, knowledge about drug interactions and adverse reactions and use of herbal drugs (Questions 1 to 14). It also included questions to elicit their attitude including concern of misuse of 
antimicrobial drugs, self-medication, and updating their knowledge of OTC medications (Questions 15 to 20). The practice-based questions elicited information regarding how they updated their information regarding OTC drugs, how they dealt with misuse and abuse of the OTC drugs and the sources for obtaining information about OTC drugs (Question 21 to 24).

\section{RESULTS}

The results of the study captured as responses to the questionnaire are depicted in the form of tables and graphs.

Table 1 indicates the correct responses to the questions which elicited the understanding and knowledge of the respondents about OTC drugs. Significant gaps were noticed in the responses from the respondents with regards to the knowledge about OTC drugs in India. Most respondents $(\mathrm{n}=47 ; 58.75 \%)$ believed that "OTC drugs" had a legal backing in India, which is not true. "OTC drugs" have not been defined or included in a separate schedule under the Drugs and Cosmetics Act. Knowledge about some common drugs (alprazolam and levofloxacin) included under Schedule H1 was inadequate. Knowledge about the dangers (GI perforation) of commonly used sodium bicarbonate containing antacids was lacking in many respondents $(n=45 ; 55.13 \%)$. A must known fact about dangers of aspirin use in children (Reye's syndrome) was also lacking in many respondents $(n=31$; $37.97 \%)$. Only $68.75 \%$ of respondents $(n=55)$ believed that OTC drugs can cause severe adverse effects.

Most of the respondents showed appropriate responses to questions regarding their attitude with regards to the OTC drugs (Table 2). Significant gaps also were present in the attitude of the respondents regarding the appropriateness of antimicrobials to be used as OTC agents $(n=11$; $13.75 \%$ ), increased risk of self-medication with OTC drugs $(n=5 ; 6.25 \%)$. Attitude regarding putting an age bar for obtaining OTC drugs $(n=5 ; 6.25 \%)$, potential for misuse of OTC drugs $(n=2 ; 2.50 \%)$ and restriction of OTC drugs $(n=12 ; 15 \%)$ can be considered to be inappropriate.

Table 1: Knowledge-based questions.

\begin{tabular}{|llll|}
\hline $\begin{array}{l}\text { SI. } \\
\text { No. }\end{array}$ & Questions & $\begin{array}{l}\text { Correct } \\
\text { response }\end{array}$ & $\begin{array}{l}\text { Participants providing } \\
\text { correct response }\end{array}$ \\
\hline $\mathbf{1}$ & $\begin{array}{l}\text { Schedule H, H1, G, X drugs can be given only with a } \\
\text { prescription of a registered medical practitioner. }\end{array}$ & Yes & $75(93.75)$ \\
\hline $\mathbf{2}$ & There is no legal recognition of OTC drugs in India. & Yes & $33(41.25)$ \\
\hline $\mathbf{3}$ & Alprazolam is in schedule H1. & Yes & $62(80.52)$ \\
\hline $\mathbf{4}$ & Levofloxacin is in schedule H. & No & $41(53.95)$ \\
\hline $\mathbf{5}$ & Morphine is an OTC drug. & No & $71(88.75)$ \\
\hline $\mathbf{6}$ & Paracetamol should not be used in jaundice. & Yes & $61(76.25)$ \\
\hline $\mathbf{7}$ & Aspirin should not be used in gastritis. & Yes & $71(88.75)$ \\
\hline $\mathbf{8}$ & $\begin{array}{l}\text { Sodium bicarbonate containing antacids has a risk of } \\
\text { perforation in peptic ulcer patients. }\end{array}$ & Yes & $35(44.87)$ \\
\hline $\mathbf{9}$ & $\begin{array}{l}\text { Prolonged use of a high dose of aspirin can cause analgesic } \\
\text { nephropathy. }\end{array}$ & Yes & $68(85)$ \\
\hline $\mathbf{1 0}$ & Aspirin should not be used in children. & Yes & $49(62.03)$ \\
\hline $\mathbf{1 1}$ & Antacids should not be used along with tetracyclines. & Yes & $50(64.10)$ \\
\hline $\mathbf{1 2}$ & OTC drugs can cause severe adverse effects. & Yes & $55(68.75)$ \\
\hline $\mathbf{1 3}$ & Fat-soluble vitamins can be used for prolonged periods. & No & $61(77.22)$ \\
\hline $\mathbf{1 4}$ & OTC herbal drugs can contain heavy metals. & Yes & $57(72.15)$ \\
\hline
\end{tabular}

Table 2: Attitude based questions.

\begin{tabular}{|llll|}
\hline $\begin{array}{l}\text { S. } \\
\text { No. }\end{array}$ & Questions & $\begin{array}{l}\text { Appropriate } \\
\text { response }\end{array}$ & $\begin{array}{l}\text { Participants providing } \\
\text { appropriate response }\end{array}$ \\
\hline $\mathbf{1 5}$ & Do you think antimicrobials should be available OTC? & No & N \\
\hline $\mathbf{1 6}$ & Do you think OTC drugs lead to frequent self-medication? & Yes & $75(96.25)$ \\
\hline $\mathbf{1 7}$ & Should there be an age bar for obtaining OTC drugs? & Yes & $75(93.75)$ \\
\hline $\mathbf{1 8}$ & $\begin{array}{l}\text { Do you think it is necessary to periodically update } \\
\text { information regarding OTC drugs? }\end{array}$ & Yes & $79(98.75)$ \\
\hline $\mathbf{1 9}$ & Are you aware of the potential of misuse of OTC drugs? & Yes & $78(97.50)$ \\
\hline $\mathbf{2 0}$ & Do you think the use of OTC drugs should be restricted? & Yes & $68(85.00)$ \\
\hline
\end{tabular}


Table 3: Practice based questions.

\begin{tabular}{|llll|}
\hline SI. No. & Questions & Yes & No \\
\hline $\mathbf{2 1}$ & Do you update your knowledge base about OTC drugs? & N $(\%)$ & N $(\%)$ \\
\hline $\mathbf{2 2}$ & Do you buy OTC drugs without a prescription? & $58(73.45)$ & $39(48.75)$ \\
\hline $\mathbf{2 3}$ & $\begin{array}{l}\text { Do you counsel others if you suspect any misuse/abuse of } \\
\text { OTC drugs? }\end{array}$ & $75(94.94)$ & $21(26.58)$ \\
\hline $\mathbf{2 4}$ & $\begin{array}{l}\text { Where do you get reliable information regarding OTC } \\
\text { drugs? }\end{array}$ & Open ended question \\
\hline
\end{tabular}

Responses to questions revealing the practices of the respondents with regards to OTC drugs are captured in Table 3 and Figure 2. Nearly half of the respondents $(n=39 ; 48.75 \%)$ have failed to update their knowledge about OTC drugs. Nearly a quarter of the respondents $(n=21 ; 26.58)$ have obtained OTC medication with a valid prescription. Majority of the respondents $(n=75 ; 94.94 \%)$ have counselled people if they suspect any misuse or abuse of OTC medications. The source of reliable information about OTC drugs in a significant number of respondents $(n=34 ; 42.5 \%)$ are from sources like the internet. Information was obtained from medical literature $(\mathrm{n}=36 ; 45 \%)$ and from peers and professionals $(\mathrm{n}=11$; $13.75 \%)$.

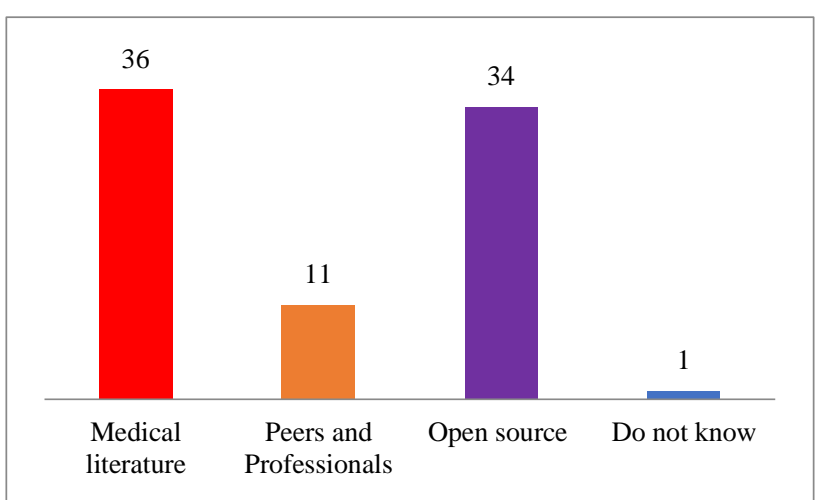

Figure 2: Open ended practice based question about source of information about OTC drugs.*

* Medical literature included medical books, pharmacopoeias, and medical journals. Peers and professionals included other medical practitioners and teachers. Open source included information from the internet and newspapers

\section{DISCUSSION}

OTC medications are not always considered safe and beneficial for patients as they can be exposed to unexpected adverse drug reactions and drug-drug and drug-food interactions. ${ }^{6}$ OTC drugs can also have potential for their misuse and abuse such as codeinebased medicines, cold and cough medications, sedative antihistamines, decongestants and laxatives. ${ }^{7}$

The dangers of self-medication are often underestimated, particularly with OTC drugs. ${ }^{3}$ Our study found that $73.42 \%$ of participants practice self-medication with OTC drugs which was similar to one study conducted by
Patil et al and Kasulkar et al in India which showed selfmedication is widely practiced among undergraduate medical students. ${ }^{8,9}$ The most common drugs implicated in self-medication include non-steroidal antiinflammatory drugs, antihistamines, gastrointestinal drugs, and antibiotics. ${ }^{10}$ Dangers with commonly used OTC drugs such as NSAIDs such as an increased risk of acute myocardial infarction occurring within one week of use have to be highlighted. ${ }^{11}$ Another study found that NSAIDs were common medications responsible for selfmedication-related to cutaneous adverse drug reactions. ${ }^{12}$

The Government of India on August 30, 2013, had made an amendment to the Drugs and Cosmetics Act of 1940 and brought the schedule $\mathrm{H} 1$ notification, but to date, there is no separate OTC drug schedule in India. ${ }^{13}$ This study reveals a gap in the knowledge, attitudes and practice among the medical interns about OTC drugs, which highlights the need for special emphasis in the undergraduate curriculum for medical students about OTC drugs.

\section{CONCLUSION}

There is a need for special emphasis and elaborate chapters in the MBBS curriculum about OTC drugs so that medical students are educated, empowered and trained with necessary skills to tackle issues arising with the use of OTC drugs. This emphasis will help the students to understand adverse drug reactions, their abuse, and misuse potential, potential drug-drug interactions and other aspects of OTC drug use.

\section{Funding: No funding sources Conflict of interest: None declared \\ Ethical approval: The study was approved by the Institutional Ethics Committee}

\section{REFERENCES}

1. Hanumantharayappa NB, Siddaiah SN. Use of over the counter drugs in urban and rural populations of Mandya district: a cross-sectional study. Int J Basic Clin Pharmacol. 2016;5:1617-21.

2. The Drugs and Cosmetics Act and Rules. Available at: https://upload.indiacode.nic.in/showfile?actid= AC_CEN_12_13_00023_194023_1523353460112\&t ype $=$ rule $\&$ filename $=$ Drugs $\% 20$ and $\% 20$ Cosmetics $\% 2$ 
0Act,\%201940\%20and\%20Rules,\%201945.pdf. Accessed on 3 September 2019.

3. Ravichandran A, Basavareddy A. Perception of pharmacists regarding over the counter medication: a survey. Indian J Pharmacol. 2016;48:729 32.

4. Meher BR, Balan S, Pugazhentni E. Knowledge, attitude and practice of over the counter drugs among dispensers working in the retail pharmacies of a South Indian city-a cross-sectional questionnaire based study. J Clin Diagnost Res. 2018;12(1):FC014.

5. Mahoney KM. The ABCs of OTCs. Available at: https://www.fda.gov/downloads/drugs/newsevents/uc m493622.pdf. Accessed on 31 January 2019.

6. Kim HJ, Yang YM, Choi EJ. Use patterns of overthe-counter (OTC) medications and perspectives on OTC medications among Korean adult patients with chronic diseases: gender and age differences. Patient Prefer Adherence. 2018;12:1597-606.

7. Cooper RJ. Over-the-counter medicine abuse- a review of the literature. J Subst Use. 2011;18(2):82107.

8. Patil SB, S H V, B V P, Santoshkumar J, Binjawadgi AS, Kanaki AR. Self-medication practice and perceptions among undergraduate medical students: a cross-sectional study. J Clin Diagn Res. 2014;8(12):HC20-3.
9. Kasulkar AA, Gupta M. Self-medication practices among medical students of a private institute. Indian J Pharm Sci. 2015;77(2):178-82.

10. Ahmad A, Patel I, Mohanta G, Balkrishnan R. Evaluation of self-medication practices in the rural area of town sahaswan in northern India. Ann Med Health Sci Res. 2014;4(S2):S73-8.

11. Bally M, Dendukuri N, Rich B, Nadeau L, HelinSalmivaara A, Garbe E, et al. Risk of acute myocardial infarction with NSAIDs in real world use: bayesian meta-analysis of individual patient data. BMJ. 2017;357:1909.

12. Patel TK, Thakkar SH, Sharma D. Cutaneous adverse drug reactions in Indian population: a systematic review. Indian Dermatol Online J. 2014;5:S76-86.

13. Hazra A. Schedule H1: hope or hype?. Indian J Pharmacol. 2014;46(4):361-2.

Cite this article as: Chatterjee S, Vijendra R, Girish $\mathrm{K}$, Koroth MHM. Assessment of knowledge, attitudes and practice among interns about over-thecounter drugs in a tertiary care hospital in India. Int $\mathbf{J}$ Basic Clin Pharmacol 2019;8:2485-9. 